\title{
Nucleic Acid Metabolism in Experimentally Hypertrophied Myocardium
}

\author{
Shinsaku Matsumoto, M.D., Toshiaki Kishir, M.D., \\ Yoshio Ito, M.D., and Tachio Kobayashi, M.D.
}

The existence of the oxidative pentose pathway in the ventricular myocardium of rat and rabbit was previously demonstrated from this

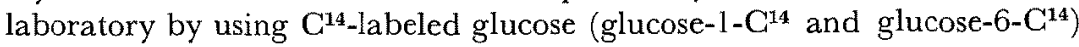
and its role was supposed to be important for the synthesis of RNA ribose in the myocardium. Though the final purpose of our intended study is to clarify the mechanism of the cardiac hypertrophy and the heart failure, the purposes of the present study are to elucidate the roles of the oxidative pentose pathway on the ribose synthesis of RNA in the rat heart muscle, and then to have an insight into the mechanism of cardiac hypertrophy, In this study, the cardiac hypertrophy due to hypertension was produced in the course of 8 to 10 weeks after the wrapping the bilateral kidneys of the Wistar rats with cellophanes. The criteria of the cardiac hypertrophy were the decrease of the DNA content in the wet unit weight and the increase of the ratio of RNA to DNA as well as the ratio of heart weight to body weight.

All the hearts of the operated group fulfilled these criteria. The magnitude of the nucleic acid synthesis via the oxidative pentose pathway was estimated as the volume difference between the $\mathrm{C}^{14}$-nucleic acid from glucose-6- $\mathrm{C}^{14}$ and that from glucose- $1-\mathrm{C}^{14}$, using the heart muscle slices incubated in $\mathrm{pH} 7.4$ phosphate buffer medium for 2 hours. In normal myocardium, about 25 per cent of RNA ribose was found to be synthesized via the oxidative pentose pathway, while that was suppressed in the hypertrophied myocardium. On the other hand, the DNA deoxyribose synthesis via this oxidative pathway could not be found in both normal and hypertrophied myocardium.

The incorporation rate of glucose- $6-\mathrm{C}^{14}$ to $\mathrm{RNA}$, e.g. the ratio of $\mathrm{C}^{14}$ RNA to the unit volume of RNA was decreased in the hypertrophied myocardium seemed to be depressed, since the incorporation rate represents likely the metabolic or functional activity. The relationship of the above mentioned results and cardiac hypertrophy or cardiac failure was also discussed in brief.

7 HE existence of the oxidative pentose pathway in the ventricular muscle of rat and rabbit heart was previously demonstrated from this laboratory

From the Department of Internal Medicine, Branch Hopital, University of Tokyo, 120 Zoshigaya Bunkyo-ku, Tokyo, Japan.

* Supported in part by the Grant from the Ministry of Education.

* This paper was presented at the 3rd APCG, Kyoto, on May 1964. 
by using $\mathrm{C}^{14}$-labeled gulcose (glucose-1- $\mathrm{C}^{14}$ and glucose-6- $\mathrm{C}^{14}$ ), and its role was supposed to be important for the synthesis of RNA ribose in the ventricular muscle.1,2) The mechanism of the cardiac hypertrophy has been studied for a long time, however, it has not yet been settled whether the cardiac hypertrophy accompany the metaplasia or not, in spite of the morphological study and the recent nucleic acid determination of the hypertrophied myocardium..$^{2-7)}$ In addition, the principal or basic property of the hypertrophied cardiac muscle seems to be only physiologically studied by a few workers, i.e. Grimm, et al. ${ }^{\text {() }}$ Whitehorn, et al. ${ }^{9)}$ and Kerr, et al. ${ }^{10}$

As the first step to clarify the mechanism of both cardiac hypertrophy and cardiac failure, the present study was carried out; (1) to elucidate the roles of the oxidative pentose pathway in the RNA ribose synthesis in the rat heart muscle, and (2) to elucidate the changes of nucleic acid metabolism in the hypertrophied myocardium which are considered to be closely related to protein synthesis.

In this study, the metaplasia was disregarded because of its small amount if any at all.

\section{Material and Method}

The ventricular enlargement or hypertrophy due to renal hypertension was produced on male Wistar rats weighing 100 to $250 \mathrm{Gm}$. by wrapping bilateral kidneys with cellophane, according to Page's method. The operated rats were killed after 8 to 10 weeks. Cardiac hypertrophy was evaluated by the ratio of heart weight to body weight and the ratio of RNA to DNT (Table I and Fig. 1).

The heart was quickly removed from the normal and the operated rats sacrificed by a blow on the head, and immediately placed in an ice cold $\mathrm{pH} 7.4$ phosphate medium. Heart muscle slices approximately $200 \mathrm{mg}$. and thickening about $0.3 \mathrm{~mm}$. were incubated in the Warburg's vessel at $37.0^{\circ} \mathrm{C}$ for 2 hours. The medium was pH 7.4 phosphate buffer containing $\mathrm{C}^{14}$-labeled substrates. The gas phase were kept always flowing $100 \%$ oxygen. Substrates were glucose-1-C ${ }^{14}$ and glucose-6$\mathrm{C}^{\mathbf{1 4}}$, and their final concentration were $1.8 \mathrm{mg} . / \mathrm{ml}$. After 2 hours incubation, slices were homogenized in ice cold water. Extraction and determination of nucleic acids were as follows:

At the first step, nucleic acids were extracted as the mixture of DNA-Na and RNA-Na composed by the procedure of Tyner, Heidelberger and Le Page, ${ }_{2}^{12)}$ and their radioactivity was determined by the gas-flow-counter.

After determination of the radioactivity of these mixtures, RNA was extracted as mononucleotide by the method of Schmidt, Thanhauser and Schneider (STS), ${ }^{13}$ ) and the radioactivity of the residue, which is the radioactivity of DNA, was also determined by the gas-flow-counter. After determining the radioactivity of DNA, this residue was analysed to DNA mononucleotide by the method of STS. The radioactivity of RNA was calculated as the difference of the radioactivity of the mixture and that of DNA. The concentration of RNA and DNA mononucleotide 
were measured by the Oricinol method and the Diphenyl Amine method respectively.

In addition, the oxidative pentose pathway was also evaluated by the radioactive carbon dioxide as a reinforcement method. The extraction and determination of the radioactive carbon dioxide were previously reported. ${ }^{11}$

The amount of $\mathrm{C}^{\mathbf{1 4}}$-nucleic acid via the oxidative pentose pathway was calculated and estimated by the formula i.e. $\left(\mathrm{C}^{14}\right.$-nucleic acid from glucose-6- $\mathrm{C}^{14}-$ $\mathrm{C}^{14}$-nucleic acid from glucose-1-C $\mathrm{C}^{14}$ ).

\section{Results}

Fig. 1 showed the relationship of heart weight and body weight as one criteria for the cardiac hypertrophy. Black dots are normal group, triangles. are operated group. It is clear that the heart weight of the operated group is larger than that of normal one. Furthermore, in order to affirm the hypertropy, DNA content and the ratio of RNA to DNA were represented in Table I.

DNA content has been considered to be proportional to the number of nuclei or cells, and the ratio of RNA to DNA has been regarded as an index of RNA content of each cell, that is, the ratio of RNA to DNA represents being proportional to the size of each cell.

Since the DNA content in the unit weight of the myocardium of the treated group was approximately half of the normal group, and the ratio of RNA to DNA of the operated group was about twice of that of normal one,

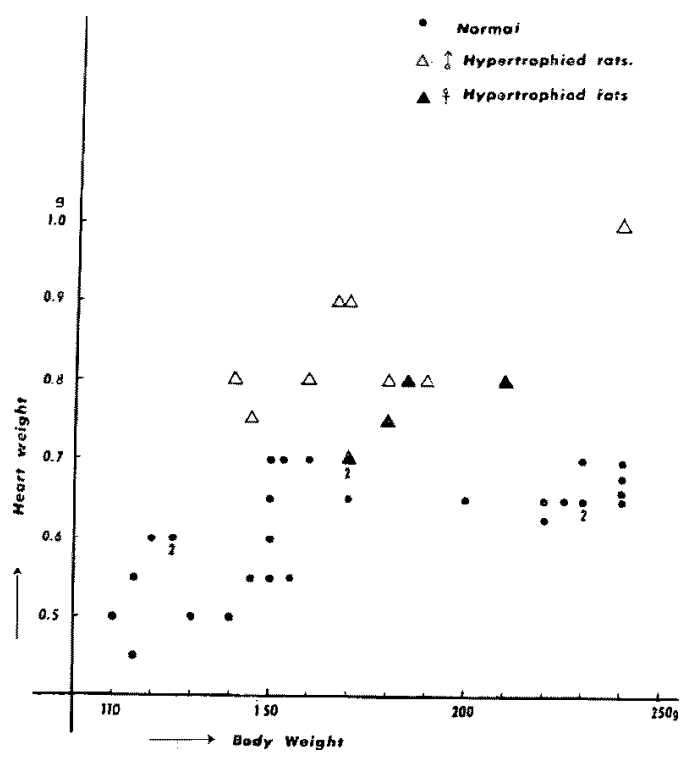

Fig. 1. Relationship of wet heart weight to body weight. 
Table I. Content of Nucleic Acids and Ratio of RNA to DNA in Ventricles

\begin{tabular}{|c|c|c|}
\hline nucleic acids tissue & Normal (N) & Hypertrophied (H) \\
\hline DNA Content & $\begin{array}{l}1.02 \\
\pm 0.25\end{array}$ & $\begin{array}{c}0.423 \quad(15)^{*} \\
\pm 0.056\end{array}$ \\
\hline RNA Content & $\begin{array}{l}0.82 \quad \text { (4) } \\
\pm 0.30\end{array}$ & $\begin{array}{c}0.575 \quad(10)^{*} \\
\pm 0.055^{(10}\end{array}$ \\
\hline RNA/DNA & $\begin{aligned} 0.70 & \\
& \pm 0.10\end{aligned}$ & $\begin{array}{l}1.57 \\
\quad \pm 0.20\end{array}$ \\
\hline
\end{tabular}

means \pm S.E. mg. of nucleic acids $/ G m$. of fresh tissue. S. E. : standard error ( ) : No. of animals. * No. of experiments of 8 animals.



these results undoubtedly indicate that the cardiac hypertrophy was produced in the operated rats.

Table II showed the results of experiments about the incorporation of $\mathrm{C}^{14}$ of glucose into nucleic acids. As for the incorporation of $\mathrm{C}^{14}$ into DNA, no difference was found in both glucose-1- $\mathrm{C}^{14}$ and glucose-6- $\mathrm{C}^{14}$, therefore, the oxidative pentose pathway seemed to be not concerned in DNA synthesis of rat myocardium. On the other hand, glucose-6-C 14 incorporated into RNA was approximately 25\% larger than glucose-1- $\mathrm{C}^{\mathbf{1 4}}$ incorporated into RNA, and so, about $25 \%$ of RNA ribose was considered to be synthesized via the oxidative pentose pathway in normal rat ventricular myocardium.

Table III showed the results of the hypertrophied rat myocardium. No difference could be found between the incorporation of glucose-1- $\mathrm{C}^{14}$ and 
Table II. Incorporation of $\mathrm{C}^{14}$ of Glucose-1- $\mathrm{C}^{14}$ and Glucose-6- $\mathrm{C}^{14}$ to DNA and RNA by the Normal Rat Heart Ventricles

\begin{tabular}{|c|c|c|c|c|}
\hline & \multicolumn{2}{|c|}{ Glucose-1-C 14} & \multicolumn{2}{|c|}{ Glucose $-6-C^{14}$} \\
\hline Incorporation to DNA & 2.14 & (5) & 2.10 & (5) \\
\hline Incorporation to RNA & 3.05 & $\begin{array}{c}(6) \\
0.02\end{array}$ & $\begin{array}{r}4.32 \\
0.05\end{array}$ & (6) \\
\hline
\end{tabular}

Values: mean \pm S.E. represented by $\mathrm{m} \mu$ moles of glucose per $\mathrm{Gm}$. of fresh tissue for 2 hours at $37^{\circ} \mathrm{G}$

Gas phase : always $100 \% \mathrm{O}_{2}$

( ): No. of animals.

n.s. : no significant

Table III. Incorporation of $\mathrm{C}^{14}$ of Glucose-1-C $\mathrm{C}^{14}$ and Glucose-6-C $\mathrm{C}^{14}$ to DNA and RNA by the Rat Hypertrophied Ventricles



Values : mean \pm S.E. represented by $\mathrm{m} \mu$ moles of glucose per $\mathrm{Gm}$. of fresh tissue for 2 hours at $37^{\circ} \mathrm{C}$

Gas phase : always $100 \% \mathrm{O}_{2}$

( ): No. of animals.

n.s. : no significant

glucose-6-C ${ }^{14}$ into RNA as well as DNA. Therefore, the RNA ribose synthesis via the oxidative pentose pathway was likely depressed in the hypertrophied myocardium. In the hypertrophied myocardium, another disturbance, that is, the decrease of the incorporation rate of $\mathrm{C}^{14}$-glucose into RNA was also found (Fig 2).

Despite an increase in RNA content, the incorporation rate i.e. $\mathrm{C}^{14}$ RNA/RNA content or the metabolic rate seems to be depressed in the hypertrophied myocardium as seen in Fig 2. Since the metabolic rate is considered as some kind of function or quality of myocardium, in spite of an increase of RNA content, its function will be regarded to be depressed in the hypcrtrophied myocardium. On the other hand, no changes could be found in both DNA content and the ratio i.e. C14-DNA/DNA content. 



Fig. 2. Metabolic rate or incorporation rate of DNA and RNA represented by the ratio of glucose incorporated to DNA and RNA to content of DNA and RNA; $\mathrm{m} \mu$ moles of glucose incorporated to nucleic acids per $\mathrm{mg}$. of nucleic acids.

\section{Discussion}

It is evident that the ventricle responds to chronic load by an increase of the myocardial mass. However, the definite conclusion is not yet drawn, whether hypertrophy accompanies a metaplasia of cells or not, although the studies on this problem have a long history. There are many histological studies. Karsner et al. ${ }^{4}$ ) concluded from their own study of 3 human hearts that the cardiac hypertrophy did not accompany any metaplasia of cells, however, Black-Schaffer and Tunner ${ }^{3)}$ reported that the abnormal increase in heart weight was due to, in part or whole, hyperplasia of cells. On the other hand, Linzbach ${ }^{14}$ ) concluded histologically that human cardiac hypertrophy was due to enlargement of each cell by the critical weight of 500 $\mathrm{Gm}$. but, over the critical level, the abnormal increase in heart weight was partially due to an increase in the number of cells. Even among the recent works using the method of DNA, RNA and protein determination, there has been discrepancy of opinion, that is, the affirmative and the negative. Summer et al. ${ }^{16)}$ and Nowy, et al. ${ }^{11}$ concluded histologically that human cardiac hypertrophy was not due to hyperplasia, but Norman, et al.7),17) reported that cardiac hypertrophy associate with some degree of hyperplasia. Widdowson, et al, investigated the water-protein-deoxyribonucleic acid relationship of the hypertrophied myocardium and argued the same conclusion as Norman, et al., because of the absence of any alternation in this relationship.

As for the mechanism of hypertrophy of each cardiac muscle fiber, Carney, et al. ${ }^{18)}$ found electromicroscopically that the hypertrophy of each cardiac muscle fiber was not due to the enlargement of both thick and thin filaments but an increase in the number of thick filaments. 
DNA is really a component of a chromosome of both animal and plant cells, and doubling of DNA precedes cell division. On the other hand, RNA is usually located in cytoplasma rather than nuclei, and of various qualities and functions. Therefore, an alternation of RNA content will be easily induced. Moreover, the protein synthesis is definitely related to an alternation in RNA content. It is possible to consider that DNA content is proportionate to the number of cells i.e. nuclei, and the ratio of RNA to DNA is proportionate to the size of cells. A decrease in DNA content or an increase in RNA/DNA without any alternation in total DNA content is therefore considered to be due to an enlargement i.e. hypertrophy of cells. In order to evaluate the hypertrophy more exactly, we used both nucleic acid determinations and the heart weight-body weight relation.

In the present study, we considered that the cardiac hyperplasia could be almost disregarded because of its small amount if any at all. The relationship between the oxidative pentose pathway and nucleic acid synthesis was one of the most important matter to examine. Despite an absence of any intimate relationship between the oxidative pentose pathway and DNA deoxyribose synthesis, approximately $25 \%$ of RNA ribose was confirmed to be synthesized via the oxidative pentose pathway and about $75 \%$ of RNA ribose via the non-oxidative one. The ratio of oxidative and non-oxidative synthesis of RNA ribose of the normal ventricular myocardium is $1: 3$, that is almost the same as the result of liver by Mark, et al. ${ }^{19)}$ Mark et al. analyzed each radioactive carbon of RNA ribose by the method of fermentation and chemical analysis, and obtained the result that the ratio of the oxidative synthesis to the non-oxidative one was $1: 3$ in liver.

It was also demonstrated that RNA ribose synthesis via the oxidative pathway was depressed in the hypertrophied myocardium, and, in order to ascertain the location of the disturbance in this pathway, $\mathrm{C}^{14} \mathrm{O}_{2}$ from glucose-1- $\mathrm{C}^{14}$ and glucose-6-C $\mathrm{C}^{14}$ were determined in both normal and hypertrophied myocardium. However, no definite results could be obtained, because of the relative unaccuracy of the methods. Therefore, it remains for further study.

Moreover, the metabolic activity of nucleic acids in hypertrophied myocardium were investigated by determining the incorporation rate, i.e. $\mathrm{C}^{14}$-DNA/DNA content and $\mathrm{C}^{14}$-RNA/RNA content. Although there could not be found any alternation in the incorporation rate of DNA in hypertrophied myocardium in comparison with normal, the incorporation rate of RNA was significantly decreased in the hypertrophied group. Of course, it is not yet settled whether the incorporation rate of nucleic acids could represent a kind of the cell or tissue function or not. However, the fairly close 
Table IV. The Oxidative Pentose Pathway Calculated by $\mathrm{C}^{14} \mathrm{O}_{2}$ for Hypertrophicd Myocardium and the Embden-Myerhof-TCA Cycle System

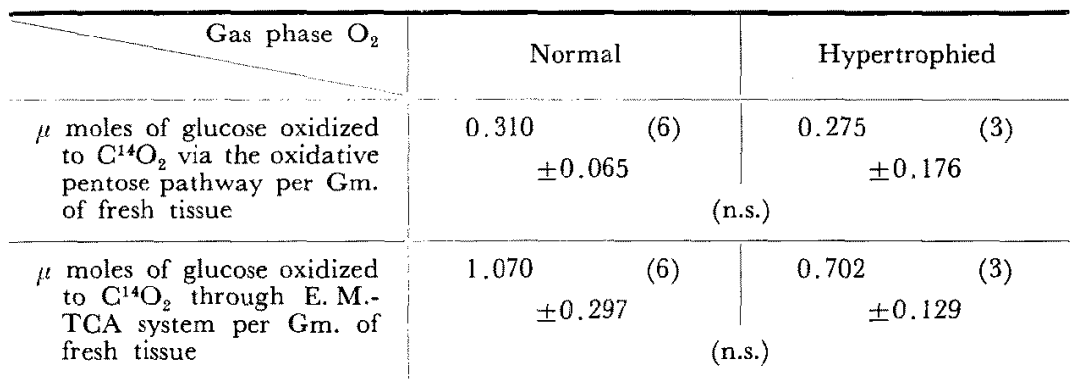

relation between RNA and protein synthesis has been demonstrated by other workers. ${ }^{20)}$ The incorporation rate of RNA, therefore, will be regarded as a kind of the function or metabolic rate of RNA. This concept agrees with that of Gudbjarnason, et al. ${ }^{20}$ They found that, despite an increase in protein synthesis of hypertrophied myocardium, the turnover rate and the incorporation rate of protein were apparently decreased.

From the reason mentioned above, our result concerning the incorporation rate of RNA seemed to indicate that the function of RNA was decreased in hypertrophied myocardium.

As for the electric phenomenon of hypertrophied myocardium, it has been reported ${ }^{9}$ that no alternation in action potential could be found, therefore, it might be said that excitability and contractility is due to some sort of metabolic changes in nucleic acids which perhaps precede the alternation in electric phenomenon and mechanical performance of hypertrophied myocardium. The causality between the metabolic changes of nucleic acids and the myocardial hypertrophy or failure remains for further study.

\section{SUMMARY}

From the experiment on the rat heart slices the following results were obtained.

(1) About 25 per cent of RNA ribose were synthesized via the oxidative pentose pathway and approximately 75 per cent via the non-oxidative one in normal ventricular myocardium. This ratio is same as that of liver.

(2) The synthesis of RNA ribose via the oxidative pentose pathway appeared suppressed in hypertrophied myocardial slices.

(3) Despite an increase in RNA content of hypertrophied myocardium, the function i.e. the incorporation rate $\left(\mathrm{C}^{14}\right.$ - $\mathrm{RNA} / \mathrm{RNA}$ content) were appar- 
ently decreased.

(4) As for the relationship between DNA and the oxidative pentose pathway, no relation could be found. Moreover, there was no change in the incorporation rate of DNA in hypertrophied myocardium employed in this study.

\section{ACKNOWLEDGEMENT}

The authors wish to express their gratitude to Associate Professor N. Hosoya for his very useful advice. Furthermore, the authors are indebted to Miss. Y. Saito, Ph.D. for the technique of extraction of nucleic acids.

\section{References}

1. Matsumoto, S., Kishii, T., Ito, Y., and Kobayashi, T. : Jap. Heart J. 3 : 555, 1962.

2. Matsumoto, S. : Jap. Heart J. 4: 131, 1963.

3. Black-Schaffer, B. and Turner, M. E. : Am. J. Path. 34: 745, 1958.

4. Karsner, T., Saphir, O., and Todd, T.: Am. J. Path. 1:351, 1925.

5. Widdowson, E. M. and McCance, R. A. : Brit. J. Exp. Path. 36: 175, 1955.

6. Nowy, H., Frings, H. D,, und Rey, K.: Experimentia 15: 70, 1959.

7. Norman, T. D. and Carter, W. J.: Fed. Proc. 20:128, 1961 (Part I).

8. Grim, A. F., Kubota, R., and Whitehorn, W. V.: Circulat. Res. 12: 118, 1963.

9. Whitehorn, W. V., Ullrick, W. C., and Anderson, B. R. : Circulat. Res. $7: 250,1959$.

10. Kerr, A., Winterberger, A. R., and Giambattista, M.: Circulat. Res. 9: 103, 1961.

11. Page, I. H.: J.A.M.A. $113: 2046,1939$.

12. Tyner, E. P., Heidelberger, C., and Le Page, G. A. : Cancer Res. 13: 186, 1953.

13. Volkin, E. and Cohn, W. E. : Methods of Biochemical Analysis, Vol. I, p. 287, 1954.

14. Linzbach, A. J.: Am. J. Cardiol. 5: 370, 1960.

15. Hoyle, T. C., III, Sumner, R. G., and McIntosh, H. D. : J. Lab. Clin. Med. 62 : 632, 1963.

16. Sumner, R. G. and McIntosh, H. D.: Circulat. Res. 12: 170, 1963.

17. Norman, T. D.: Prog. Cardiovas. Dis. $4: 439,1962$.

18. Carney, J. A. and Brown, A. A., Jr.: Am. J. Path. 44; 521, 1964 ,

19. Marks, P. A. and Feigelson, P. : J. Biol. Chem. 226 : 1001, 1957.

20. Gudbjarnason, S., Telerman, M., Chiba, C., Wolf, P. L., and Bing, R. J. : J. Lab. Clin. Med. $63: 245,1964$. 